\title{
Calibration of atmospheric hydrogen measurements
}

\author{
A. Jordan and B. Steinberg \\ Max-Planck-Institute for Biogeochemistry (MPI-BGC), Jena, Germany \\ Received: 8 October 2010 - Published in Atmos. Meas. Tech. Discuss.: 12 November 2010 \\ Revised: 18 February 2011 - Accepted: 10 March 2011 - Published: 11 March 2011
}

\begin{abstract}
Interest in atmospheric hydrogen $\left(\mathrm{H}_{2}\right)$ has been growing in recent years with the prospect of $\mathrm{H}_{2}$ being a potential alternative to fossil fuels as an energy carrier. This has intensified research for a quantitative understanding of the atmospheric hydrogen cycle and its total budget, including the expansion of the global atmospheric measurement network. However, inconsistencies in published observational data constitute a major limitation in exploring such data sets. The discrepancies can be mainly attributed to difficulties in the calibration of the measurements. In this study various factors that may interfere with accurate quantification of atmospheric $\mathrm{H}_{2}$ were investigated including drifts of standard gases in high pressure cylinders. As an experimental basis a procedure to generate precise mixtures of $\mathrm{H}_{2}$ within the atmospheric concentration range was established. Application of this method has enabled a thorough linearity characterization of the commonly used $\mathrm{GC}-\mathrm{HgO}$ reduction detector. We discovered that the detector response was sensitive to the composition of the matrix gas. Addressing these systematic errors, a new calibration scale has been generated defined by thirteen standards with dry air mole fractions ranging from $139-1226 \mathrm{nmol} \mathrm{mol}^{-1}$. This new scale has been accepted as the official World Meteorological Organisation's (WMO) Global Atmospheric Watch (GAW) $\mathrm{H}_{2}$ mole fraction scale.
\end{abstract}

\section{Introduction}

Following some early measurements of atmospheric hydrogen (Schmidt, 1974), this trace gas has received little attention for many years. In the past decade, interest in the atmospheric $\mathrm{H}_{2}$ budget has increased significantly as scenarios for a future hydrogen economy have been developed

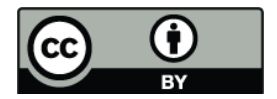

Correspondence to: A. Jordan (ajordan@bgc-jena.mpg.de)
(Prather, 2003). The main concern about potentially rising levels of atmospheric hydrogen is an additional consumption of hydroxyl radicals which in turn would increase the lifetime of greenhouse gases such as methane. Growing $\mathrm{H}_{2}$ mixing ratios would also increase stratospheric water vapour concentrations with implications for the energy balance and the ozone budget of the stratosphere. Reliable model predictions require quantitative information of the processes controlling the natural hydrogen cycle. The current knowledge as well as gaps in our understanding of the global atmospheric $\mathrm{H}_{2}$ budget have been reviewed recently (Ehhalt and Rohrer, 2009). Atmospheric concentration data provide key information for this understanding. A number of time series of $\mathrm{H}_{2}$ observations at several sites with some global representation were started between the mid 1980s and the early 1990s (Khalil and Rasmussen, 1990; Novelli et al., 1999; Langenfelds et al., 2002). In the absence of a long-term trend in the past two decades the source and sink processes are believed to be in balance (Grant et al., 2010a). Atmospheric hydrogen data have been explored using ChemistryTransport Models and inverse model calculations (see references in Ehhalt and Rohrer, 2009). Most of these studies are based on data from the cooperative flask sampling network run by NOAA-ESRL-GMD. Discrepancies between this data set and observations from the AGAGE network have been revealed (Masarie et al., 2001). These inconsistencies led to different trends and seasonal variations for the same measurement site revealing the limits of a meaningful interpretation of atmospheric $\mathrm{H}_{2}$ records. Evaluating the comparability of these two data sets for the period of 1994-2004 Xiao et al. (2007) have established a mean offset of $1.45 \%$ between NOAA and AGAGE data and have applied a corresponding factor to harmonize the data sets. However, this factor does not account for possible concentration dependent differences of the calibration scales and averages out temporal changes of the offset. In the absence of a common calibration scale for $\mathrm{H}_{2}$, multiple scales have been listed in the literature with

Published by Copernicus Publications on behalf of the European Geosciences Union. 
largely unknown conversion factors (Schmidt, 1974; Khalil and Rasmussen, 1990; Novelli et al., 1999; Bonasoni et al., 1997; Francey et al., 1996). Therefore, an assessment of the comparability of the different data sets is very difficult. As a consequence, the establishment of a common calibration scale for $\mathrm{H}_{2}$ has been one of the goals listed in the WMO Global Atmospheric Watch Strategic Plan 2008-2015 (WMO, 2007). One major difficulty to maintain a stable $\mathrm{H}_{2}$ scale has been the occurrence of significant drifts of $\mathrm{H}_{2}$ mixing ratios in standard gas cylinders over time (Masarie et al., 2001; Bonasoni et al., 1997), which are likely to have contributed to inconsistencies in various time series.

All published atmospheric $\mathrm{H}_{2}$ measurements have been carried out using gas chromatography with a mercuric oxide reduction detector. Only very recently, alternative technologies suited for routine operation have been described (Novelli et al., 2009; Necki et al., 2009). The $\mathrm{HgO}$ reduction detector has a non-linear response, which demands a careful characterization using multiple calibration points. In turn, this makes the quantification sensitive to the applied response function and the range of mixing ratios of the calibration standards.

In view of the described difficulties associated with calibration of $\mathrm{H}_{2}$ measurements a European research project for investigating the biogeochemistry of $\mathrm{H}_{2}$ (EuroHydros) included activities to set up an accurate calibration scale for improving the consistency of the various data sets. Studies that were performed within this project included long-term background air monitoring (Grant et al., 2010a; Yver et al., 2010; Bond et al., 2011), observations in urban environments (Steinbacher et al., 2007; Vollmer et al., 2007; Aalto et al., 2009; Hammer et al., 2009; Yver et al., 2009; Grant et al., 2010b) and soil uptake studies (Hammer and Levin, 2009; Lallo et al., 2009; Simmonds et al., 2011). Hydrogen mixing ratios detected in these experiments span from the detection limit to more than $1000 \mathrm{ppb}$. Here we describe the development of a new calibration scale ranging from 139 to $1226 \mathrm{nmol} \mathrm{mol}^{-1}$ (parts-per-billion, ppb).

\section{Experimental section}

Three conditions are required for the accurate determination of hydrogen in air: a precise analytical method, stable reference standards and an accurate assignment of $\mathrm{H}_{2}$ mixing ratios to these standards.

\subsection{Analytical method}

Air samples were measured using a Reduction Gas Analyser (RGA) 3 (Trace Analytical, Menlo Park, CA, USA) that is based on gas chromatographic separation with subsequent $\mathrm{HgO}$ reduction and photometric $\mathrm{UV}$ detection of $\mathrm{Hg}$ (Schmidt and Seiler, 1970). The instrument is equipped with a pre-column of Unibeads $1 \mathrm{~S}\left(1 / 8^{\prime \prime} \times 0.8 \mathrm{~m}, 60 / 80 \mathrm{mesh}\right)$ connected in series with an analytical column containing Molecular Sieve $5 \AA\left(1 / 8^{\prime \prime} \times 0.8 \mathrm{~m}, 60 / 80 \mathrm{mesh}\right)$ through a 2-position, 10-port injection valve (ET6C10UWE, VICI, Schenkon, $\mathrm{CH}$ ) and a $1 \mathrm{~mL}$ sample loop. The 10-port injection valve configuration allows the pre-column to be back flushed, thus preventing other reducible trace gases from reaching the analytical column and detector. Synthetic air (Westfalen AG, Muenster, Germany) is used as the carrier gas at a flow of $25 \mathrm{~mL} \mathrm{~min}^{-1}$. The $\mathrm{GC}$ and detector ovens are kept constant at $106^{\circ} \mathrm{C}$ and $272{ }^{\circ} \mathrm{C}$, respectively. The sample is first flushed through the sample loop for $36 \mathrm{~s}$ at a flow of $70 \mathrm{~mL} \mathrm{~min}^{-1}$. After the sample flow is stopped the sample loop pressure is allowed to relax to ambient pressure for $20 \mathrm{~s}$ before the injection valve is switched to start the analysis. The $\mathrm{H}_{2}$ retention time is $49 \mathrm{~s}$, CO elutes at $104 \mathrm{~s}$. The flow direction in the pre-column is reversed at $78 \mathrm{~s}$. Because of the characteristic baseline noise and tailing peak shape of the detector the performance of the peak integration algorithm is crucial for the overall performance. The analogue output from the RGA3 is digitized using an analogue-to-digital converter (35900E, Agilent Technologies, Santa Clara, CA, USA) and integrated using the Agilent Chemstation software (Version A.08.03). Quantification is based on the sample peak height normalized to the mean $\mathrm{H}_{2}$ peak height of the bracketing analysis pair of the working reference gas.

Measurements of atmospheric hydrogen are made relative to a set of standard gases in high pressure cylinders. Two external gas selection valves allow 6 standards and an additional 16 flasks to be analyzed in series, always alternating with a gas aliquot from a single working reference cylinder. For the period of the experiments the raw peak heights of this working reference were stable within $\pm 3.3 \%$. The $\mathrm{HgO}$ reaction bed had been in use for five years. Major response changes have been observed after power failures but no such incident had occurred since September 2007. Three of the standard ports are permanently occupied by quality control air standards at 500, 650 and $1200 \mathrm{ppb}$ that are generally analyzed on a daily basis.

\subsection{Air standard production}

These standard gases are natural air samples, filled at the Max-Planck-Institute for Biogeochemistry using an oil-free compressor (Rix Sweet Air 6A 5-L, Rix Industries, Benicia, CA, USA) with anhydrous magnesium perchlorate as the drying agent. To generate standards with a sub-ambient $\mathrm{H}_{2}$ mixing ratio air was depleted of $\mathrm{H}_{2}$ by directing the compressor flow through a cartridge filled with a hydrogen scrubber (Sofnocat 423, $775 \mathrm{~g}$, plus Sofnocat 514, $1000 \mathrm{~g}$, Molecular Products, Thaxed, UK). Standards with higher mixing ratios were produced by admixture of varying amounts of commercial compressed air (Linde AG, Leipzig, Germany) containing a high $\mathrm{H}_{2}$ mixing ratio. The $\mathrm{H}_{2}$ mixing ratios of these standards have been initially assigned relative to a single standard gas with $543 \mathrm{ppb} \mathrm{H}_{2}$ provided by CSIRO, Division 
Table 1. Set of reference standards.

\begin{tabular}{|c|c|c|c|c|c|c|}
\hline \multirow[t]{2}{*}{ Cylinder ID $^{\mathrm{a}}$} & \multirow[t]{2}{*}{$p$ [bar] } & \multirow[t]{2}{*}{ filling date } & \multicolumn{2}{|c|}{$\mathrm{H}_{2}[\mathrm{ppb}]$} & \multirow{2}{*}{$\begin{array}{c}\sigma^{\mathrm{c}} \\
{[\mathrm{ppb}]}\end{array}$} & \multirow{2}{*}{$\begin{array}{r}\text { PDD residuals } \\
{[\mathrm{ppb}]}\end{array}$} \\
\hline & & & CSIRO94 ${ }^{\mathrm{b}}$ & MPI-2009 & & \\
\hline ESX-0803237 & 60 & 26 Apr 2007 & 134.6 & 139.4 & 0.4 & -0.6 \\
\hline GM-26/470-3 & 22 & 13 Feb 2007 & 274.0 & 289.2 & 0.4 & 0.3 \\
\hline GM-24/635-22 & 22 & 7 Feb 2007 & 399.8 & 415.5 & 0.3 & -0.1 \\
\hline ESX-0803222 & 60 & 22 Aug 2004 & 456.0 & 471.7 & 0.3 & 0.5 \\
\hline ESX-0803231 & 60 & 4 Aug 2004 & 492.4 & 507.8 & 0.3 & 0.2 \\
\hline Lin-B0892/92 & 200 & 10 Jun 2003 & 512.2 & 529.2 & 0.4 & 1.0 \\
\hline Lux-3502361 & 200 & 22 Nov 2004 & 562.4 & 581.1 & 0.7 & 0.1 \\
\hline Lin-B0873/92 & 200 & $22 \mathrm{Feb} 2007$ & 604.1 & 622.7 & 0.5 & -0.7 \\
\hline ESX-0500421 & 60 & 10 Dec 2005 & 664.2 & 685.2 & 0.9 & -0.5 \\
\hline GM-26/470-2 & 22 & 15 Feb 2007 & 731.4 & 754.0 & 1.1 & -1.0 \\
\hline GM-24/635-2 & 22 & 7 Feb 2007 & 824.8 & 854.6 & 0.7 & 0.2 \\
\hline GM-26/470-1 & 22 & 9 Feb 2007 & 937.9 & 970.4 & 1.9 & 0.8 \\
\hline GM-24/635-30 & 22 & 5. Apr 2006 & 1185 & 1225.6 & 2.1 & -0.3 \\
\hline
\end{tabular}

a ESX-: Essex Cryogenics 34 L stainless steel cylinder; GM-24/: Graeven Metalltechnik 27 L stainless steel cylinder; GM-26/Graeven Metalltechnik 50 L stainless steel cylinder; Lin-: Linde 50 L stainless steel cylinder; Lux-: Luxfer UK 50 L aluminium cylinder.

${ }^{\mathrm{b}}$ CSIRO94 assignments done by MPI-BGC. See text.

c $\sigma$ : standard error of the mean of the average analysis results of the individual measurement rounds in the period September-December 2008 .

${ }^{\mathrm{d}}$ Residuals of the calibration of the GC-PDD instrument: $\left(\mathrm{H}_{2}\right.$ assigned) - (measured $\left.\mathrm{H}_{2}\right)$.

of Marine and Atmospheric Research, Aspendale, Australia in 2002. This enabled the link to the $\mathrm{H}_{2}$ CSIRO94 calibration scale used by the AGAGE monitoring network (Francey et al., 1996; Simmonds et al., 2000). The preliminary characterization of the non-linearity of the $\mathrm{HgO}$-reduction detector response was made using a set of 18 flask samples that were prepared with variable proportions of a standard air containing about $800 \mathrm{ppb} \mathrm{H}_{2}$ and $3000 \mathrm{ppbCH}_{4}$, respectively, and synthetic, $\mathrm{H}_{2}$ - and $\mathrm{CH}_{4}$-free air. The $\mathrm{H}_{2}$ mixing ratios ranged from 100 to $800 \mathrm{ppb}$, with 6 data points in the atmospheric range (400-600 ppb). The dilution factor for the individual samples was calculated from the quotient of the $\mathrm{CH}_{4}$ mixing ratio in the sample to the $\mathrm{CH}_{4}$ mixing ratio in the undiluted standard. Methane was analyzed by a GC flame ionisation detector (FID) which exhibits a good linearity in the specified range. With a quadratic response function established for the $\mathrm{HgO}$-reduction detector in this experiment the $\mathrm{H}_{2}$ mixing ratios of the standard gases in high pressure cylinders were preliminarily assigned (see column "CSIRO94" in Table 1). As one approach to verify the stability of the standards, aliquots from five of these standards were filled into low pressure 5-L glass flasks equipped with one valve with PCTFE sealing. This amount of sample has enabled repeated analysis over five years, which allowed to monitor the relative stability of $\mathrm{H}_{2}$ mixing ratios of the flask samples compared to the set of high-pressure cylinder standard gases.

\subsection{Method description: set-up for generating new standard gas mixtures}

With the procedure described in the section above a set of calibration standards was produced that ensured a consistent data set. However, the various calibration transfer steps as well as the unknown uncertainty of the CSIRO94 calibration scale made it difficult to assess its accuracy. In order to achieve assignments with better traceable accuracies, a method to precisely produce $\mathrm{H}_{2}$ gas mixtures was set up and evaluated. The technique described in this section is based on dilution of a known volume of pure hydrogen with a known mass of hydrogen-free real air that has been prepared using the compressor system described in the previous section. The volume is defined by a stainless steel sample loop connected to a two position, 10 port valve (ET6C10UWM, VICI, Schenkon, $\mathrm{CH}$ ). The volume determination is made as follows: the sample loop is quantitatively filled with degassed, high-purity water and weighed several times on a calibrated balance (AT261, Mettler-Toledo, Giessen, Germany) until weight loss due to evaporation is apparent. To calculate the volume the density of water at the measured temperature is used. The mass of the displaced air in the sample loop is also accounted for (corresponding to $0.11 \%$ of the liquid water mass). For assessing the reproducibility of this measurement the filling and weighing procedure was performed 10 times in a row and the whole procedure was repeated on three different days. When the sample loop is connected to the Valco valve an additional volume of $2.46 \mu \mathrm{L}$ has to be accounted for, which results from the channel in the valve 


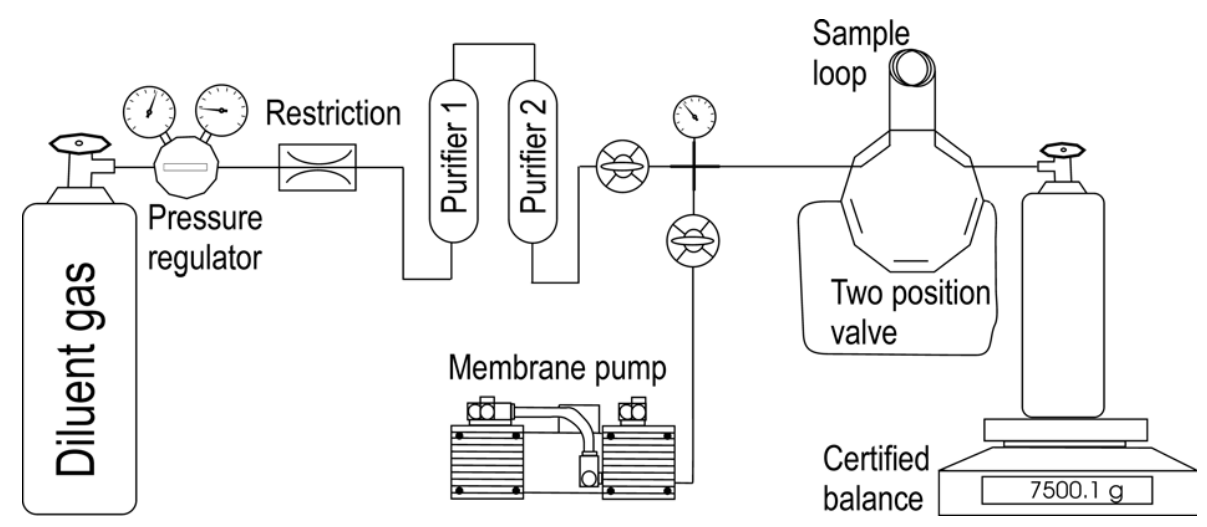

Fig. 1. Set-up of the system for mixing hydrogen and purified air.

rotor and from the boreholes of the employed valve (J. Kurrmann, personal communication, 2005). Most experiments were performed using a sample loop of $344.6 \mu \mathrm{L}$ volume. Before starting the dilution of hydrogen the amount of diluent air needed for the targeted mixing ratio is calculated for the given amount of $\mathrm{H}_{2}$. The number of moles of $\mathrm{H}_{2}$ is determined according to the gas law (taking into account non ideal behaviour of the pure gas):

$n\left(\mathrm{H}_{2}\right)=\frac{p \cdot V}{R \cdot T} \cdot\left(1+\frac{B}{V_{\mathrm{mol}}}\right)$

with $p=$ atmospheric pressure $[\mathrm{Pa}], V=$ volume of sample loop +internal volume of the valve $[\mathrm{L}] ; R=$ ideal gas constant $=8314.51 \cdot(\mathrm{PaL}) /(\mathrm{K} \mathrm{mol}) ; T=$ temperature $[\mathrm{K}]$; $B=$ virial coefficient for $\mathrm{H}_{2}=0.015 \mathrm{~L} \mathrm{~mol}^{-1}$ (Kehiaian, 1997); $V_{\mathrm{mol}}=$ molar volume $=R \cdot T / p$.

The corresponding mass of diluent air $\left(m_{\text {air }}\right)$ needed for a targeted mixing ratio then corresponds to:

$m_{\text {air }}=M_{\text {air }} \cdot n_{\mathrm{H}_{2}} /$ mixing ratio

with $M_{\text {air }}=$ molar mass of air $=28.965 \mathrm{~g} \mathrm{~mol}^{-1}$ (Tohjima et al., 2005; Wieser et al., 2009).

Initially, sample loop and valve are stored for a few hours in a thermo insulating foam box to ensure a homogeneous temperature of sample loop, valve and a PT100 thermocouple (GTF 175, Greisinger electronic, Regenstauf, Germany). The two valve ports adjacent to the ports that are occupied by the sample loop are coupled via stainless steel capillaries (1 m each, 1/16" OD, 0.04" ID; Valco, Schenkon, $\mathrm{CH}$ ) with a hydrogen generator (Parker-Balston 75-32, Haverhill, MA, USA) and a vent, respectively. The procedure consists of the following steps:

$\mathrm{H}_{2}$ is filled in the sample loop by flushing it for $15 \mathrm{~s}$ with a total volume of $>100 \mathrm{~mL}$ of pure hydrogen. The flow is then stopped, and following a pressure equilibration time of $20 \mathrm{~s}$, the valve is switched to isolate the sample loop contents. The temperature of the sample loop and the ambient pressure measured using a high precision barometer (DPI142,
Druck GE Sensing, Leicester, UK) are recorded. Subsequently, the interior of the valve is flushed with several liters of $\mathrm{N}_{2}$ to ensure that no $\mathrm{H}_{2}$ other than the amount captured inside the sample loop remains inside the valve. The two capillaries that were in contact with pure $\mathrm{H}_{2}$ are detached. Next, the valve is installed in a panel illustrated in Fig. 1. In this assembly one of the valve ports adjacent to the sample loop is coupled to an evacuated 5-L high-pressure aluminium cylinder (AA7060 hoop wrap, Luxfer, Nottingham, UK) that is resting on a balance (CP8201-0CE, Sartorius, Goettingen, Germany verified model with EC type approval). Before each filling of the mixing cylinder the balance is calibrated using internal calibration weights. The internal calibration is verified using an external $5000.0 \mathrm{~g}$ weight and the tare weight of the evacuated cylinder without connecting line is subsequently determined. The second valve position adjacent to the loop is connected to a cross piece that makes a connection to the diluent gas, a pressure gauge and a vacuum pump allowing for the evacuation of the connecting line. The diluent gas cylinder is equipped with a pressure regulator that allows to adjust back pressures up to 200 bar (SL401, Rotarex, Luxembourg) and connected to two $500 \mathrm{~mL}$ stainless steel cartridges (316L-50DF4-500, Swagelok, Solon, $\mathrm{OH}$ ) with a crimped restrictor capillary ( $\left.1 \mathrm{~m}, 1 / 16^{\prime \prime} \mathrm{OD}, 0.005^{\prime \prime} \mathrm{ID}\right)$. For removing any residual $\mathrm{H}_{2}$ in the diluent air the steel cartridges are filled with catalyst scrubbers (Sofnocat 423, $700 \mathrm{~g}$, and Sofnocat 514, $400 \mathrm{~g}$, respectively, Molecular Products Inc., Thaxted, UK).

After installing the sample loop valve on this panel all inter-connecting stainless steel lines are evacuated and flushed with the diluent air three times to exclude any remaining contaminations. Then, the transfer of the hydrogen is started by the following steps in direct sequence: first the head valve of the evacuated high pressure cylinder is opened, the sample loop valve is switched to put the sample loop in line and the air flow is started by opening the respective membrane valve. For the restriction in the given set-up an initial back-pressure of $100 \mathrm{bar}$ is set with the pressure 


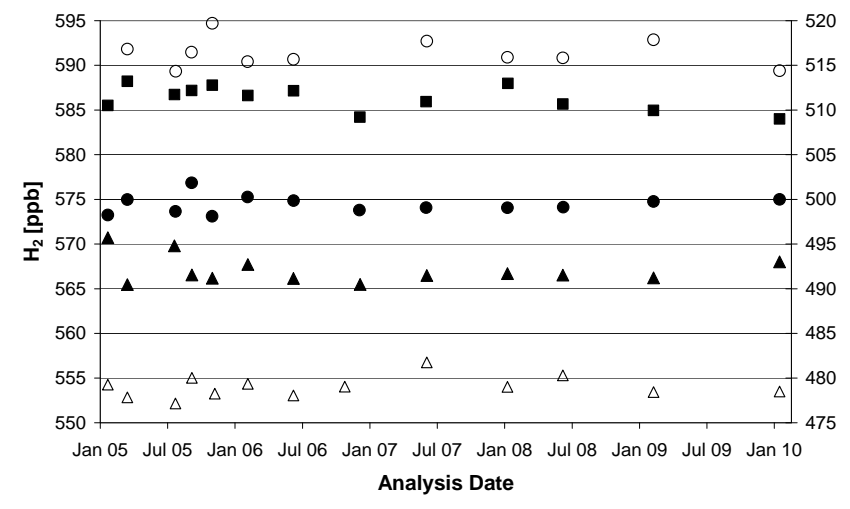

Fig. 2. Storage test of $\mathrm{H}_{2}$ in air samples stored in glass flasks over five years. Filled symbols refer to the left axis, open symbols to the right axis.

regulator resulting in a flow of $2.5 \mathrm{~L} \mathrm{~min}^{-1}$ standard pressure. After flushing the sample loop with about $100 \mathrm{~L}$ of air quantitative transfer of the $\mathrm{H}_{2}$ can be assumed. At this point the cylinder is closed, the flow is stopped and the sample loop valve is removed for remaining within the maximum pressure limit of the Valco valve ( $400 \mathrm{psi})$. The 5 -L cylinder is directly connected to the cross-piece as depicted in Fig. 1. Following a further three cycles of evacuation and flushing of the connecting lines the remaining air is transferred until the required mass for the targeted mixing ratio is reached. After removal of the transfer tubing the cylinder mass is weighed to determine the exact amount of added diluent gas.

Finally, the gas mixtures are analysed on the GC-HgO detector repeatedly. After analysis some of the mixtures are partly blown off through a $1 / 16^{\prime \prime}$ capillary, their mass is weighed and a new mixture is produced by dilution with additional hydrogen-free air. Analysis of non-diluted mixtures after the pressure release did not reveal any change of the $\mathrm{H}_{2}$ mixing ratio due to a fractionation during the blowing-off process.

A series of 53 hydrogen-in-air mixtures in the range of $12-1252 \mathrm{ppb}$ was prepared by the above described mixing technique during September-December 2008 and thoroughly analysed to characterize the response curve of the detector. A list of the individual mixtures and their analysis results is given in Table 2. To verify the stability of the detector response during this period several rounds of analysis of the 13 standard gases listed in Table 1 have been conducted in addition to the daily analysis of the quality control standard gases.

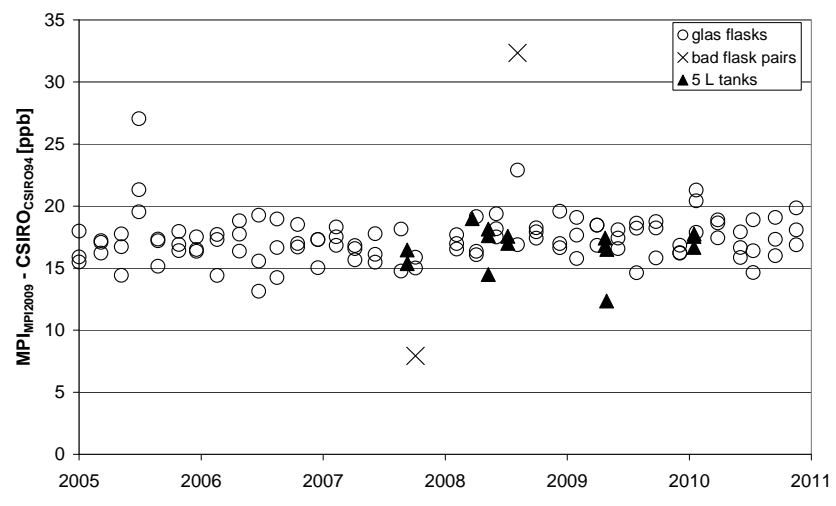

Fig. 3. Time series of $\mathrm{H}_{2}$ intercomparison results between MPI and CSIRO. Circles represent the differences of the mean results of two flask pairs filled with the same air with each pair being analysed in either laboratory ("Sausage Flask Intercomparison" program, IMECC 2011). Two flask pairs with large pair deviations $(>10 \mathrm{ppb})$ are flagged by crosses. Triangles correspond to the difference of standard measurements in $5 \mathrm{~L}$ high pressure cylinders.

\section{Results and discussion}

\subsection{Reference gas stability}

Various container types have been tested for their suitability of storing $\mathrm{H}_{2}$ standard gases. A precondition for this stability test is a fixed reference point that is known not to drift. As such reference the set of 13 calibration standards listed in Table 1 has been chosen. Support for the assumption that these standard gases are stable comes from the record of $\mathrm{H}_{2}$ mixing ratio measurements of aliquots from the 5-L glass flasks samples. No detectable change of $\mathrm{H}_{2}$ was observed in these samples relative to the set of calibration standards over five years (Fig. 2). Additional evidence for the stability of the reference standard set is provided by results from an ongoing bi-monthly flask intercomparison exercise ("Sausage Flask Intercomparison"; IMECC, 2011) that has been extended in recent years by a regular exchange of standards in small cylinders. As shown in Fig. 3 the inter-laboratory offset of $\mathrm{H}_{2}$ measurements between MPI and CSIRO has remained constant over time.

About 100 air standards in various types of high pressure cylinders were analysed repeatedly for periods of one to six years to judge the stability of their $\mathrm{H}_{2}$ mixing ratios. If an increase in the $\mathrm{H}_{2}$ mixing ratio of more than $3 \mathrm{ppb}$ is observed for air containing ambient levels of $\mathrm{H}_{2}(400-650 \mathrm{ppb})$ this is assumed to reflect a true drift, while smaller differences may just reflect the longer term uncertainty of the measurements. This assessment criterion is based on the results of the routine quality control gas standard analysis. Over the period of Apr 2007 through Aug 2009 a standard deviation of $\leq 1.6 \mathrm{ppb}$ was observed for the daily means of three standards with $\mathrm{H}_{2}$ in the range from 500 to $680 \mathrm{ppb}$ (Fig. 4). A larger scatter was observed for the quality control standard at $1200 \mathrm{ppb} \mathrm{H}_{2}$ 

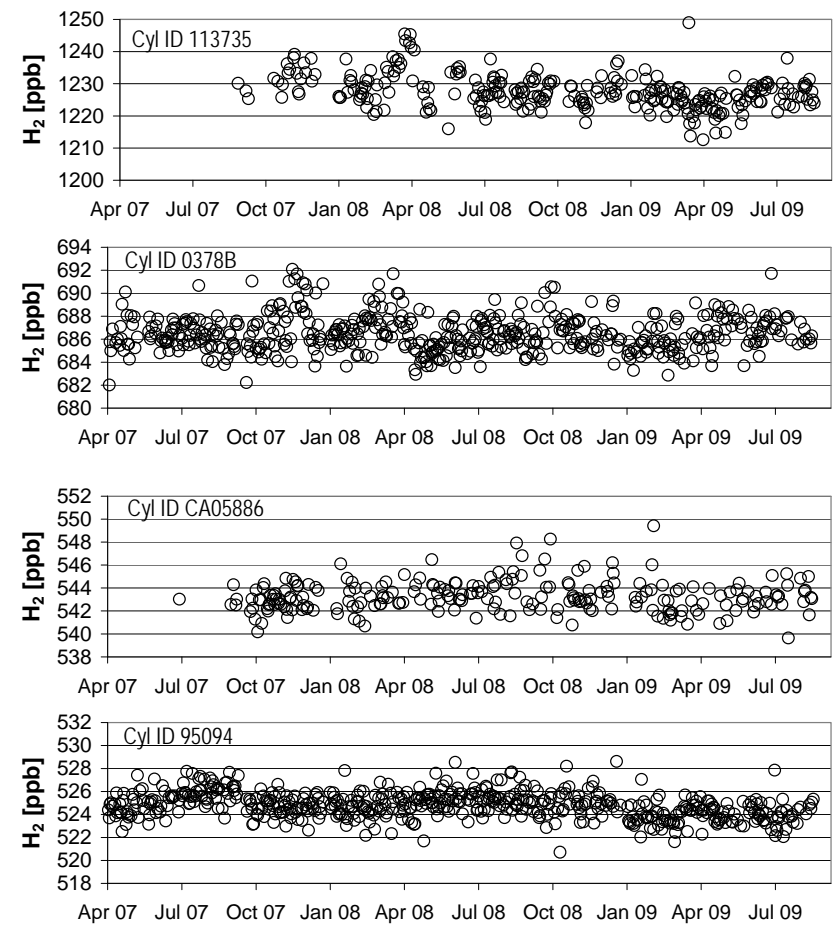

Fig. 4. Time series of quality control standard gas analysis results.

(std. dev. $=5 \mathrm{ppb}$ ). Hence, $\mathrm{a} \mathrm{H}_{2}$ drift in air standards exhibiting mixing ratios of $650-1200 \mathrm{ppb}$ is assumed significant if the absolute change exceeds $1 \%$ of its $\mathrm{H}_{2}$ mixing ratio.

Figure 5 summarizes the $\mathrm{H}_{2}$ drift rates observed in sets of standards grouped by cylinder type relative to the reference set. High pressure cylinders made from steel or stainless steel generally kept stable $\mathrm{H}_{2}$ levels irrespective of variations in the specific material (normal steel, tempering steel 34CrMo4, stainless steel 304L, 316L 316 Ti), the surface passivation procedures (pickling, electropolishing or mechanical surface finishing), valve type, size or manufacturer. In contrast, highly variable storage properties where observed in aluminium cylinders. For the aluminium cylinder type that is most commonly used for standards of greenhouse gases (N150; Luxfer, Riverside, CA, USA) (NOAA, 2010) only about $40 \%$ of the cylinders tested were found to keep stable $\mathrm{H}_{2}$ mixing ratios; some cylinders showed very small $\mathrm{H}_{2}$ drifts and others featured large $\mathrm{H}_{2}$ increases. In addition, the hydrogen drift rates of standard gases in 5-L cylinders manufactured from different aluminium alloys have been compared. The most commonly used alloy AA6061 is an aluminium-magnesium-silicon blend (Aluminium Association, 2010). The cylinder manufactured from this material exhibited an increase of $\mathrm{H}_{2}$ which is significantly higher and longer-lasting compared to that in cylinders of the alloys AA2001 (major alloying element $\mathrm{Cu}$ ) and AA7060 (major alloying element $\mathrm{Zn}$ ) (Fig. 6). In these latter containers the $\mathrm{H}_{2}$ mixing ratio stabilized within a few months after an initial lower drift. These different properties may reflect the

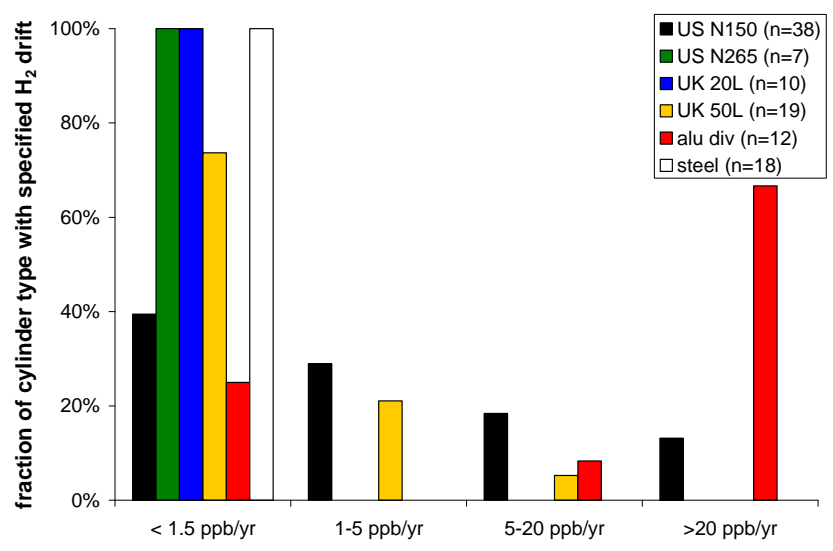

Fig. 5. Hydrogen drift rates in air stored in different high pressure cylinder types. The first two bars represent standards stored in Luxfer US aluminium cylinders US N150 (29 L) purchased from Scott Marrin Inc., Riverside (CA), USA; US N265 (46 L) purchased from Conwin Carbonic Co., Los Angeles (CA), USA; blue and yellow bars (UK $20 \mathrm{~L}$ and 50 L) represent Luxfer UK aluminium cylinders (purchased from MATAR, Mazzano, Italy); further aluminium cylinders of various origins and sizes are grouped in the red column "alu div"; all steel cylinders tested are presented in the white column.

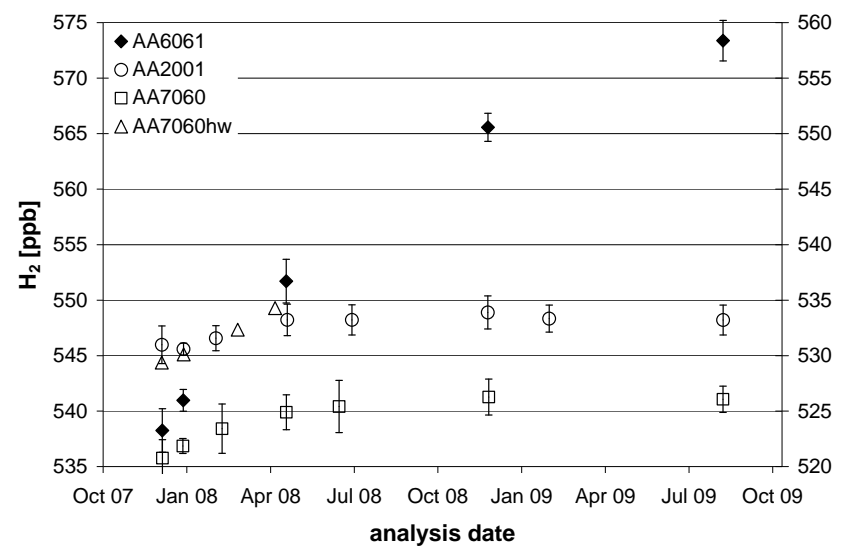

Fig. 6. Dependence of $\mathrm{H}_{2}$ growth rate in air on aluminium cylinder alloy. Symbols represent individual cylinders; black circles refer to the left axis, open symbols refer to the right axis. Data of the cylinder used for the standard mixing procedure (AA7060hw) are illustrated by triangles.

influence of alloying additions on the characteristic trait of the material. Aluminium surfaces are generally covered by a chemically inert passivation layer of amorphous $\mathrm{Al}_{2} \mathrm{O}_{3}$. However, the integrity of this layer is affected by the alloying additions and by organic residues or metallic particles from the manufacturing process (Ostermann, 1998). The specific annealing, quenching and aging processes during the manufacturing cycle also have a major impact on the nature of the surface layer (Beyer et al., 1986). Finally, this layer is very hard and may develop small cracks upon mechanical 
Table 2. $\mathrm{H}_{2}$-in-air mixtures prepared by the mixing procedure.

\begin{tabular}{|c|c|c|c|c|c|c|c|c|c|c|}
\hline \multirow[t]{2}{*}{ Sample ID } & \multicolumn{2}{|c|}{ Production Analysis } & \multirow{2}{*}{$\begin{array}{r}\mathrm{H}_{2} \\
{[\mathrm{ppb}]}\end{array}$} & \multirow[t]{2}{*}{ signal $^{\mathrm{a}}$} & \multirow{2}{*}{$\begin{array}{c}\sigma^{\mathrm{b}} \\
{[\%]}\end{array}$} & \multirow[t]{2}{*}{$n^{\mathrm{c}}$} & \multicolumn{2}{|c|}{ residual $^{\mathrm{d}}$} & \multicolumn{2}{|c|}{$u_{\operatorname{mix}}^{\mathrm{e}}[\%]$} \\
\hline & date & date & & & & & [ppb] & {$[\%]$} & random & total \\
\hline 20083923 & 26 Nov 08 & 27 Nov 08 & 12.4 & 0.021 & 10.7 & 18 & & & 0.3 & 0.39 \\
\hline 20083894 & 25 Nov 08 & 25 Nov 08 & 49.8 & 0.068 & 1.7 & 5 & 0.1 & 0.21 & 0.19 & 0.32 \\
\hline 20084077 & 9 Dec 08 & 9 Dec 08 & 99.2 & 0.141 & 1.2 & 14 & 1.2 & 1.2 & 0.26 & 0.36 \\
\hline 20083352 & 16 Oct 08 & 16 Oct 08 & 142.9 & 0.214 & 1.2 & 20 & -0.6 & 0.39 & 0.15 & 0.30 \\
\hline 20084065 & 8 Dec 08 & 9 Dec 08 & 158.1 & 0.237 & 1.3 & 20 & 1.3 & 0.84 & 0.25 & 0.35 \\
\hline 20083893 & 24 Nov 08 & 25 Nov 08 & 171.8 & 0.262 & 1.0 & 37 & 0.4 & 0.23 & 0.15 & 0.30 \\
\hline 20083671 & 3 Nov 08 & 5 Nov 08 & 192.7 & 0.300 & 1.1 & 68 & -0.1 & 0.07 & 0.17 & 0.31 \\
\hline 20083557 & 27 Oct 08 & 28 Oct 08 & 223.2 & 0.356 & 0.87 & 28 & 0.1 & 0.04 & 0.18 & 0.31 \\
\hline 20083261 & 7 Oct 08 & 8 Oct 08 & 265.9 & 0.441 & 0.67 & 14 & -1.5 & 0.58 & 0.15 & 0.30 \\
\hline 20084105 & $12 \mathrm{Dec} 08$ & 15 Dec 08 & 269.9 & 0.446 & 0.55 & 47 & -0.1 & 0.02 & 0.16 & 0.30 \\
\hline 20083408 & 17 Oct 08 & 17 Oct 08 & 287.8 & 0.485 & 0.65 & 17 & -1.6 & 0.57 & 0.17 & 0.31 \\
\hline 20083534 & 23 Oct 08 & 24 Oct 08 & 317.9 & 0.543 & 0.53 & 25 & 0.1 & 0.04 & 0.19 & 0.31 \\
\hline 20083450 & 20 Oct 08 & 20 Oct 08 & 318.1 & 0.543 & 0.49 & 30 & 0.5 & 0.17 & 0.17 & 0.31 \\
\hline 20083787 & 11 Nov 08 & 14 Nov 08 & 334.5 & 0.576 & 0.56 & 53 & 0.8 & 0.24 & 0.13 & 0.29 \\
\hline 20083880 & 19 Nov 08 & 21 Nov 08 & 349.0 & 0.610 & 0.44 & 33 & -0.5 & 0.14 & 0.18 & 0.31 \\
\hline 20083282 & 9 Oct 08 & 9 Oct 08 & 361.2 & 0.637 & 0.49 & 38 & -1.1 & 0.30 & 0.17 & 0.30 \\
\hline 20083348 & 14 Oct 08 & 15 Oct 08 & 382.8 & 0.680 & 0.38 & 40 & 0.3 & 0.08 & 0.16 & 0.30 \\
\hline 20083295 & 13 Oct 08 & 13 Oct 08 & 414.1 & 0.750 & 0.38 & 20 & -0.1 & 0.03 & 0.13 & 0.28 \\
\hline 20083670 & 30 Oct 08 & 3 Nov 08 & 438.8 & 0.806 & 0.34 & 59 & -0.5 & 0.12 & 0.14 & 0.29 \\
\hline 20083554 & 27 Oct 08 & 27 Oct 08 & 452.6 & 0.832 & 0.44 & 25 & 1.4 & 0.32 & 0.14 & 0.29 \\
\hline 20083821 & 17 Nov 08 & 18 Nov 08 & 472.1 & 0.879 & 0.36 & 27 & 0.0 & 0.00 & 0.18 & 0.31 \\
\hline 20083351 & 15 Oct 08 & 16 Oct 08 & 472.1 & 0.882 & 0.42 & 39 & -1.0 & 0.21 & 0.08 & 0.27 \\
\hline 20083533 & 22 Oct 08 & 23 Oct 08 & 498.0 & 0.935 & 0.40 & 34 & 1.5 & 0.29 & 0.15 & 0.29 \\
\hline 20083260 & 7 Oct 08 & 8 Oct 08 & 527.0 & 1.004 & 0.40 & 39 & 0.5 & 0.09 & 0.12 & 0.28 \\
\hline 20084012 & 8 Dec 08 & 8 Dec 08 & 540.3 & 1.037 & 0.27 & 11 & -0.5 & 0.09 & 0.19 & 0.31 \\
\hline 20083114 & 25 Sep 08 & $26 \mathrm{Sep} 08$ & 540.4 & 1.037 & 0.38 & 32 & -0.2 & 0.04 & 0.08 & 0.27 \\
\hline 20083733 & 6 Nov 08 & 9 Nov 08 & 555.3 & 1.071 & 0.30 & 61 & 0.2 & 0.03 & 0.19 & 0.32 \\
\hline 20083449 & 17 Oct 08 & 20 Oct 08 & 576.7 & 1.121 & 0.45 & 44 & 0.1 & 0.01 & 0.08 & 0.27 \\
\hline 20083462 & 21 Oct 08 & 21 Oct 08 & 598.1 & 1.171 & 0.32 & 27 & 0.1 & 0.01 & 0.08 & 0.27 \\
\hline 20083891 & 21 Nov 08 & 23 Nov 08 & 626.2 & 1.237 & 0.33 & 40 & 0.2 & 0.04 & 0.08 & 0.27 \\
\hline 20083115 & 26 Sep 08 & 29 Sep 08 & 627.2 & 1.242 & 0.47 & 52 & -1.0 & 0.16 & 0.08 & 0.27 \\
\hline 20083786 & 11 Nov 08 & 11 Nov 08 & 647.7 & 1.286 & 0.20 & 34 & 1.1 & 0.17 & 0.08 & 0.27 \\
\hline 20083028 & 16 Sep 08 & 17 Sep 08 & 668.8 & 1.340 & 0.35 & 39 & -0.5 & 0.07 & 0.08 & 0.27 \\
\hline 20083062 & 17 Sep 08 & 19 Sep 08 & 670.7 & 1.346 & 0.37 & 59 & -1.2 & 0.18 & 0.08 & 0.27 \\
\hline 20083553 & 24 Oct 08 & 27 Oct 08 & 695.5 & 1.400 & 0.31 & 68 & 1.2 & 0.17 & 0.08 & 0.27 \\
\hline 20083820 & 14 Nov 08 & 17 Nov 08 & 724.6 & 1.472 & 0.34 & 58 & 0.5 & 0.07 & 0.14 & 0.29 \\
\hline 20083668 & 28 Oct 08 & 29 Oct 08 & 751.7 & 1.537 & 0.31 & 43 & 0.3 & 0.05 & 0.08 & 0.27 \\
\hline 20083860 & 17 Nov 08 & 20 Nov 08 & 778.9 & 1.600 & 0.28 & 39 & 1.7 & 0.21 & 0.14 & 0.29 \\
\hline 20083711 & 6 Nov 08 & 7 Nov 08 & 805.6 & 1.667 & 0.19 & 34 & 1.1 & 0.14 & 0.15 & 0.29 \\
\hline 20083954 & 28 Nov 08 & 1 Dec 08 & 825.0 & 1.716 & 0.24 & 51 & 0.3 & 0.04 & 0.15 & 0.29 \\
\hline 20083297 & 14 Oct 08 & 14 Oct 08 & 849.4 & 1.779 & 0.35 & 19 & -1.2 & 0.14 & 0.08 & 0.27 \\
\hline 20083283 & 10 Oct 08 & 13 Oct 08 & 851.2 & 1.782 & 0.37 & 46 & -0.5 & 0.05 & 0.08 & 0.27 \\
\hline 20083669 & 29 Oct 08 & 30 Oct 08 & 868.1 & 1.828 & 0.29 & 45 & -2.3 & 0.27 & 0.08 & 0.27 \\
\hline 20082905 & 10 Sep 08 & 10 Sep 08 & 889.8 & 1.877 & 0.57 & 15 & -0.6 & 0.07 & 0.08 & 0.27 \\
\hline 20083404 & 16 Oct 08 & 17 Oct 08 & 896.6 & 1.890 & 0.30 & 40 & 0.8 & 0.09 & 0.08 & 0.27 \\
\hline 20084102 & $10 \mathrm{Dec} 08$ & 10 Dec 08 & 939.3 & 1.995 & 0.21 & 15 & 1.2 & 0.13 & 0.13 & 0.28 \\
\hline 20084104 & $11 \mathrm{Dec} 08$ & 12 Dec 08 & 969.0 & 2.074 & 0.22 & 28 & -1.2 & 0.12 & 0.11 & 0.28 \\
\hline 20083710 & 5 Nov 08 & 6 Nov 08 & 1011 & 2.180 & 0.24 & 43 & -1.5 & 0.15 & 0.09 & 0.27 \\
\hline 20083816 & 14 Nov 08 & 14 Nov 08 & 1052 & 2.276 & 0.19 & 20 & 0.8 & 0.08 & 0.09 & 0.27 \\
\hline 20083953 & 27 Nov 08 & 28 Nov 08 & 1099 & 2.399 & 0.36 & 46 & -0.5 & 0.04 & 0.09 & 0.27 \\
\hline 20084103 & $11 \mathrm{Dec} 08$ & 11 Dec 08 & 1181 & 2.602 & 0.18 & 19 & 1.4 & 0.12 & 0.09 & 0.27 \\
\hline 20083850 & 18 Nov 08 & 19 Nov 08 & 1249 & 2.778 & 0.35 & 40 & 0.3 & 0.02 & 0.09 & 0.27 \\
\hline 20084080 & 10 Dec 08 & 10 Dec 08 & 1252 & 2.787 & 0.31 & 24 & -0.6 & 0.05 & 0.09 & 0.27 \\
\hline
\end{tabular}

a signal $=$ average normalized peak height relative to the working standard containing $\mathrm{H}_{2}=523.8$ ppb (SampleID 20061951), ${ }^{b} \sigma=$ relative standard deviation of the analysis, ${ }^{c} n=$ number of GC-HgO-analysis, ${ }^{d}$ residual $=\mathrm{H}_{2}$ mixing ratio measured based on the calibration function (Eq. 3 ) $-\mathrm{H}_{2}$ mixing ratio resulting from the moles of $\mathrm{H}_{2}$ and moles of air mixed, ${ }^{\mathrm{e}} u_{\mathrm{mix}}=$ uncertainty of the mixing procedure: random $=$ combined uncertainty of pressure, temperature and mass measurements, total $=$ combined uncertainty of all parameters that influence the mixing procedure as specified in Table 3. 
stress (Bever, 1986). As the porous alumina layer contains adsorbed water (Paglia et al., 2004) corrosion processes at these surface defects of aluminium cylinders can produce small amounts of hydrogen. In summary, there are various influencing factors that can explain why aluminium cylinders do not generally behave like chemically inert $\mathrm{Al}_{2} \mathrm{O}_{3}$ surfaces. On the basis of the tests performed within this study it is not possible to clearly prove the specific reasons that determine the characteristics of an individual cylinder. However, the different processes discussed can explain the variability of individual cylinders of the same type as well as systematic differences between cylinder types or cylinders from different manufacturers.

\subsection{Evaluation of the mixing procedure}

To evaluate the accuracy of the method for producing gas mixtures with defined $\mathrm{H}_{2}$ mixing ratios several limiting factors have been considered. These include sensor and balance accuracies, gas purities, analytical precision and surface effects. A summary of the quantitative estimates of the relative contribution of each factor to the uncertainty of the standard composition is given in Table 3 .

The accuracies of the balances and the barometer have been directly controlled by the German calibration service (DKD), the calibration of the PT100 temperature sensor was verified using a calibrated high-precision thermometer (DP251, Omega, Stamford, CT, USA). The measured temperature of the sample loop when it was filled with $\mathrm{H}_{2}$ was within a narrow range for all mixtures (296.9-298.3 K). The typical diurnal amplitude of the laboratory temperature variation was $\sim 0.5 \mathrm{~K}$ (peak-to-peak). Based on this, the temperature homogeneity in the insulating foam box is assumed to be within $0.1 \mathrm{~K}$. The volume measurement of the sample loop is based on a weighing of water and such depends on the water density that is also a function of the temperature. These gravimetric operations were performed at 295-298 K, similar to the temperature conditions during the mixing experiments. Temperature variations in the weighing laboratory were always below $0.5^{\circ} \mathrm{C}$, rendering the temperature influence on the density a minor effect. Other systematic errors may include the level of filling with water and the uncertainty of the internal volume of the valve (including fittings). The relative contribution of these errors to the total uncertainty would change with a variation of the sample loop size. However, experiments performed using alternative loops with different volumes $(245.8 \mu \mathrm{L}, 379.9 \mu \mathrm{L}, 1511 \mu \mathrm{L})$ yielded consistent results and did not reveal any systematic loop size dependence. The correction from the ideal gas law that is made by applying the second virial coefficient is very small $(0.06 \%)$ and the uncertainties associated with this coefficient are considered to be negligible.

A blank determination of the diluent gases using the GC$\mathrm{HgO}$ method did not provide a rigorous purity assessment, because of the non-sufficient detection limit of the analytical
Table 3. Contributing factors to the uncertainty of the $\mathrm{H}_{2}$ mixing procedure.

\begin{tabular}{|c|c|c|c|}
\hline Variable & Source of error & uncertainty & $\begin{array}{l}\text { relative } \\
\text { uncertainty }\end{array}$ \\
\hline$p$ & sensor accuracy & $\pm 7 \mathrm{~Pa}^{\mathrm{a}}$ & $0.01 \%{ }^{1}$ \\
\hline \multirow[t]{3}{*}{$T$} & sensor accuracy & $\pm 0.2 \mathrm{~K}^{\mathrm{b}}$ & $0.07 \%^{1}$ \\
\hline & $T$ inhomogeneity & $< \pm 0.1 \mathrm{~K}^{\mathrm{c}}$ & $0.03 \%^{1}$ \\
\hline & total $T$ uncertainty & $\mathrm{d}$ & $0.08 \% 1$ \\
\hline$m$ (air) & balance accuracy & $\pm 0.16 \mathrm{~g}^{\mathrm{a}, \mathrm{d}}$ & $0.02-0.24 \%{ }^{1 *}$ \\
\hline$\rho$ (air) & composition uncertainty & $\mathrm{e}$ & $<0.01 \%^{2}$ \\
\hline \multirow[t]{5}{*}{$V$} & balance accuracy & $\pm 0.05 \mathrm{mg}^{\mathrm{a}}$ & $0.01 \%^{2}$ \\
\hline & filling error & $\pm 0.3 \mu \mathrm{L}^{\mathrm{f}}$ & $0.04 \%^{2}$ \\
\hline & water density & $\pm 0.12 \mathrm{~g} \mathrm{~L}^{-1 \mathrm{~g}}$ & $0.01 \%^{2}$ \\
\hline & internal valve vol. & $< \pm 0.5 \mu \mathrm{L}^{\mathrm{h}}$ & $0.14 \%^{2}$ \\
\hline & total $V$ uncertainty & $\mathrm{d}$ & $0.15 \%^{2}$ \\
\hline virial coefficient & & $<20 \%$ i & $<0.02 \%{ }^{2}$ \\
\hline \multirow[t]{3}{*}{ Gas purity } & $\mathrm{H}_{2}$ purity & $<0.001 \% \mathrm{j}$ & $<0.001 \% 3$ \\
\hline & $\mathrm{H}_{2}$ blank of diluent & $<+1 \mathrm{ppb}^{\mathrm{k}}$ & $0.20 \%{ }^{4}$ \\
\hline & $\mathrm{H}_{2}$ from $\mathrm{Al}$ surface & $<+0.2 \mathrm{ppb}^{1}$ & $<0.04 \%{ }^{4}$ \\
\hline \multicolumn{2}{|c|}{ total error standard mixing } & $\mathrm{d}$ & $0.3 \%$ \\
\hline \multicolumn{2}{|c|}{ regression fit error } & $0.5 \mathrm{ppb}^{\mathrm{m}}$ & $0.1 \%$ \\
\hline \multicolumn{2}{|c|}{$\mathrm{GC}-\mathrm{HgO}$ analysis } & $1.6 \mathrm{ppb}^{\mathrm{n}}$ & $0.3 \%$ \\
\hline \multicolumn{2}{|c|}{ total error at atmospheric mixing ratios } & $\mathrm{d}$ & $0.5 \%$ \\
\hline
\end{tabular}

${ }^{a}$ DKD (German calibration service) calibration certificate; ${ }^{b}$ checked with calibrated thermometer; ${ }^{c}$ estimate from observed lab temperature variability; ${ }^{d}$ root of sum of error squares; ${ }^{\mathrm{e}}$ estimate from literature (Park et al., 2004; Tohjima et al., 2005; NOAA, 1976); ${ }^{\mathrm{f}}$ reproducibility $(1 \sigma){ }^{\mathrm{g}}$ water density range of observed weighing lab temperature variability; ${ }^{\mathrm{h}}$ estimate of maximum additional fitting volume; ${ }^{\mathrm{i}}$ estimate based on the number of significant digits quoted in the literature; ${ }^{j}$ manufacturer specification; ${ }^{\mathrm{k}}$ blank analysis using GC-HePDD; ${ }^{1}$ drift over 5 days taken from storage experiment (s. Fig. 6); ${ }^{\mathrm{m}}$ see Table 1 , last column; ${ }^{\mathrm{n}}$ scatter of daily averages of the quality control standard analysis $(1 \sigma)$ (s. Fig. 4)

${ }^{1}$ random and systematic influence; ${ }^{2}$ systematic bias; ${ }^{3}$ bias resulting in systematically lower mixing ratios; ${ }^{4}$ bias resulting in systematically higher mixing ratios

* the relative uncertainty of the mass determination varies depending on the actual sample mass and the number of intermediate weighing steps

method ( $\sim 10 \mathrm{ppb})$. In order to check for the completeness of the catalytic removal of hydrogen in the diluent gas, experiments for the dilution of $\mathrm{H}_{2}$ were performed at different flow rates. Thus, the residence times of the diluent in the purifying cartridge were varied. An increase in $\mathrm{H}_{2}$ mixing ratios that points to a non-quantitative removal of $\mathrm{H}_{2}$ in the dilution air was observed at flow rates exceeding $5 \mathrm{~L} \mathrm{~min}^{-1}$. Therefore, special care was taken that the flow rate of the gas transfer was always restricted to $2.5 \mathrm{~L} \mathrm{~min}^{-1}$ at maximum. The absence of a significant blank in such dilution air has been verified using a new analytical system based on gas chromatography with a pulsed-discharge photo ionization detector that has been installed recently (GC-HePDD; VICI, Schenkon, CH) (Novelli et al., 2009). A chromatogram of diluent air with this instrumentation indicated a very small peak below the detection limit of $<1 \mathrm{ppb}$. However, this test could only be done by hindsight as the system has been set up after the production series of standard mixtures had been completed. 
The palladium diffusion cell that is utilized in the hydrogen generator is specified to reach a hydrogen purity of $>99.99999 \%$. This excludes a significant contribution of any hydrogen impurity to the uncertainty of the method.

In contrast, it is essential to exclude loss of $\mathrm{H}_{2}$ or contamination with excess $\mathrm{H}_{2}$ during any of the steps of the experiment. As pointed out earlier, a $\mathrm{H}_{2}$ increase has been identified in air samples stored in aluminium cylinders. This renders this type of container unsuitable for long-term storage of reference gases. Therefore, the air mixtures generated with the mixing procedure were not kept as reference standards but served to assign values to standards in containers with superior storage properties. These latter cylinders have a larger mass exceeding the weighing range of the balance available which excluded their direct use for preparation of gravimetric mixtures. Therefore, the requirement for stable hydrogen mixing ratios in the 5-L aluminium cylinder applies only to the relatively short time of the experiment including the time for analysing the gas mixture. A storage test with an air sample in the cylinder used for the experiment was showing an initial $\mathrm{H}_{2}$ growth rate of $0.04 \mathrm{ppb} \mathrm{d}^{-1}$ (depicted by triangles in Fig. 6). Within a maximum period of 5 days between generation of a mixture and its analysis this growth rate does not cause any detectable alteration of the composition.

There is also the potential for a loss of $\mathrm{H}_{2}$ within the process. Significant differences in the permeation rates of hydrogen relative to oxygen or nitrogen have been described for various polymers including polyarylethers (Wang et al., 2002) and fluorinated polymers (Monson et al., 2009). One polymer part that is in contact with the $\mathrm{H}_{2}$ during the preparation of the gas mixtures is the rotor of the two position valve. This may result in some $\mathrm{H}_{2}$ diffusing into the valve rotor material while the sample loop is isolated between the filling and transfer to the evacuated cylinder, which takes about 6 min. To investigate this effect several mixtures were prepared with two different rotor polymer types and variable holding times. A decrease of the detected $\mathrm{H}_{2}$ at longer waiting periods was observed for mixtures, which had been prepared using a valve equipped with a Valcon-E rotor (polyarylether/PTFE polymer composite; VICI, Schenkon, $\mathrm{CH}$ ). This finding suggests a loss of hydrogen by diffusion into this polymer. No such depletion was apparent for mixtures prepared with Valcon-M rotors (hydrocarbon polymer; VICI, Schenkon, $\mathrm{CH})$ for holding times up to two hours. Therefore, all standard mixtures discussed here were prepared with Valcon Mrotors.

The residuals from the best regression fit of the GC-HgOreduction measurement data of the set of $53 \mathrm{H}_{2}$-in-air mixtures (see Sect. 3.3) provide an experimental measure of the combined uncertainty contributed by the precision limits of the mixing procedure and the measurement error. In Table 2 the random components of the procedure's uncertainty (related to the precision limits of the pressure, temperature and mass determinations) are summed up for each mixture taking the square root of the sum of the individual error squares

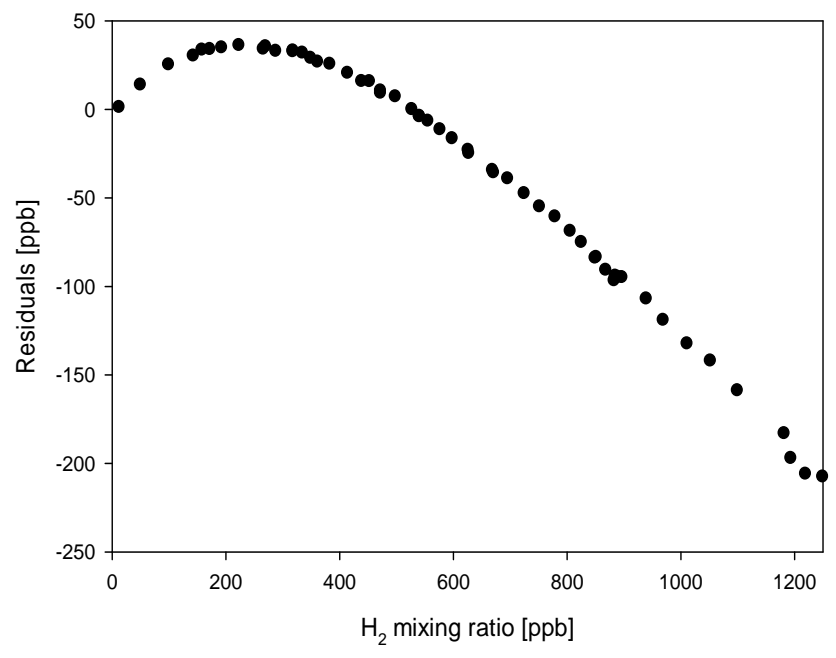

Fig. 7. Residuals of a linear regression fit of the $\mathrm{GC}-\mathrm{HgO}$ detector signals for the set of $53 \mathrm{H}_{2}$-in-air mixtures. Displayed is the difference: $\left(\mathrm{H}_{2}\right.$ amount mixed)-(measured $\mathrm{H}_{2}$ mixing ratio) based on a one point calibration.

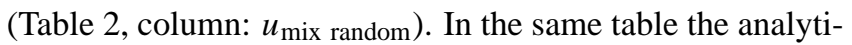
cal precision and the residuals of the regression fit are specified. The combined measurement and random mixing uncertainty is on average $0.12 \%$ for the mixtures with $\mathrm{H}_{2}$ mixing ratios above $300 \mathrm{ppb}$ which complies very well with the observed relative residuals. More relevant for the accuracy of the procedure are systematic errors associated with the measured parameters and other influencing factors. These do not average out with increasing sample number but can cause a systematic bias. Including the potential systematic errors identified in Table 3 results in an estimate of the relative uncertainty of $0.3 \%$ for the mixing procedure (see Table 2, last column).

\subsection{HgO reduction detector response function}

A series of 53 mixtures in the range of $12-1250 \mathrm{ppb}$ was prepared by the above described mixing technique during September-December 2008 (Table 2). The relationship between signal response and actual mixing ratio is highly nonlinear (Fig. 7). Systematic, concentration dependent residuals are apparent in 2nd and 3rd order polynomial regression functions (Fig. 8). In contrast, a combination of a quadratic and exponential function of the following type (3) results in a good match between measured and calculated data points:

$$
\left[\mathrm{H}_{2}\right]=a x^{2}+b x+c \cdot\left(1-e^{-d x}\right)
$$

$a, b, c, d=$ regression parameters; $x=$ peak height normalised to working standard.

This response function type is the result of the detection principle including an exponential relationship from the Lambert-Beer law of the UV absorption detection of the 


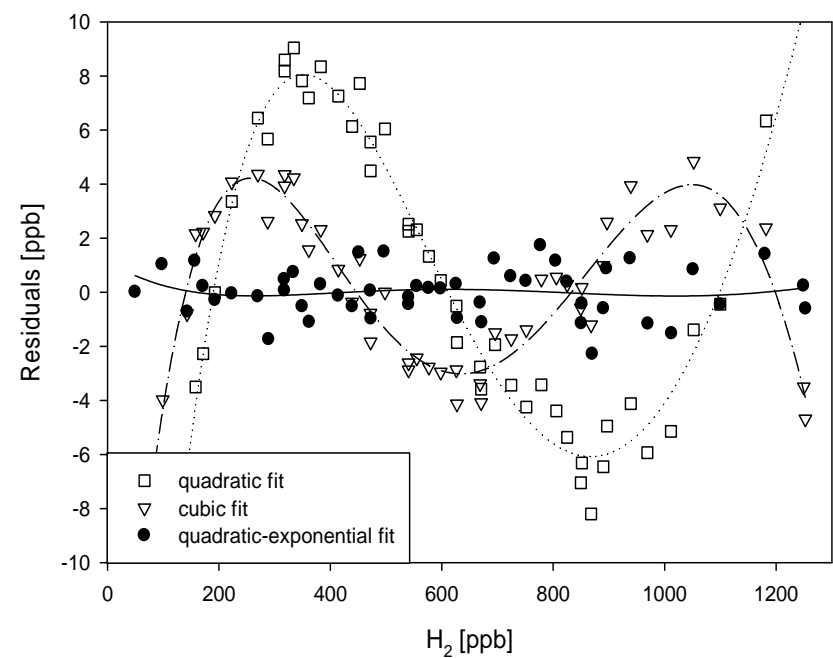

Fig. 8. Residuals for various regression functions through the set of $\mathrm{H}_{2}$-in-air mixtures. Displayed is the difference: $\left(\mathrm{H}_{2}\right.$ amount mixed)-(measured $\mathrm{H}_{2}$ mixing ratio) based on the respective regression function.

mercury vapour as well as an influence from the chemical reaction of the $\mathrm{HgO}$ reduction.

In addition to the mixtures in air, some 50 mixtures were prepared with nitrogen, purified using a gas cleaning cartridge certified for high pressure and $<1 \mathrm{ppb}$ impurity levels (Aeronex 70KFI4R, Mykrolis, San Diego, CA, USA). Over the entire observed mixing ratio range the signal heights of $\mathrm{H}_{2}$ mixing ratios in nitrogen were consistently $0.6 \%$ higher than in the corresponding $\mathrm{H}_{2}$-in-air mixtures with the same $\mathrm{H}_{2}$ content (Fig. 9). Additional mixtures of $\mathrm{H}_{2}$ in argon, in oxygen, and mixtures with various fractions of nitrogen in air or oxygen in air show a clear anti-correlation of the $\mathrm{H}_{2}$ signal response relative to the fraction of oxygen (Fig. 10). This influence of oxygen on the detector sensitivity can be explained by an overlap of the chromatographic peaks of hydrogen and oxygen. Although oxygen does not directly generate any signal at the $\mathrm{HgO}$ reduction detector it can re-oxidize some of the $\mathrm{Hg}$ that is produced by the reduction of $\mathrm{HgO}$ through $\mathrm{H}_{2}$. Thus, oxygen reduces the detector signal strength. This matrix sensitivity requires that quantification of $\mathrm{H}_{2}$ in air samples be done by calibration of the detector using $\mathrm{H}_{2}$-in-air mixtures as standard gases. Reference gases in nitrogen or any other gas would result in a bias.

Using the calibration function described above (excluding the lowest data point which was at the detection limit of the $\mathrm{HgO}$-reduction detector) the $\mathrm{H}_{2}$ mixing ratios of the suite of 13 standard gases of the reference set were reassigned (Table 1, column MPI-2009). The difference of the two scales at ambient mixing ratios matches the offset observed in the MPI-CSIRO intercomparison activities (see Fig. 3). Recent analysis of these gases using the GC-HePDD with a linear detector response resulted in absolute residuals below $1 \mathrm{ppb}$ (see Table 1, last column). This finding provides independent

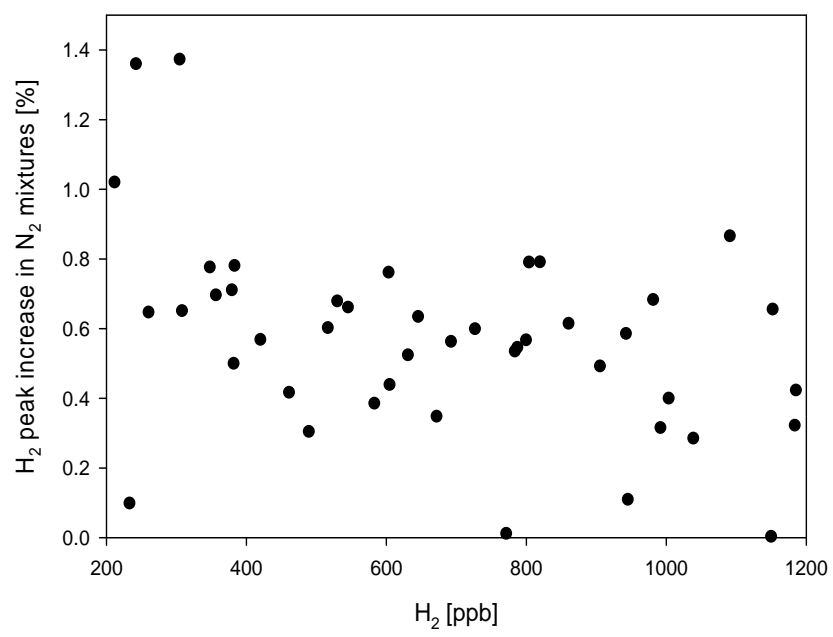

Fig. 9. Relative increase of the normalized $\mathrm{H}_{2}$ peak height in $\mathrm{N}_{2}$ mixtures compared to $\mathrm{H}_{2}$ in air mixtures [\%].

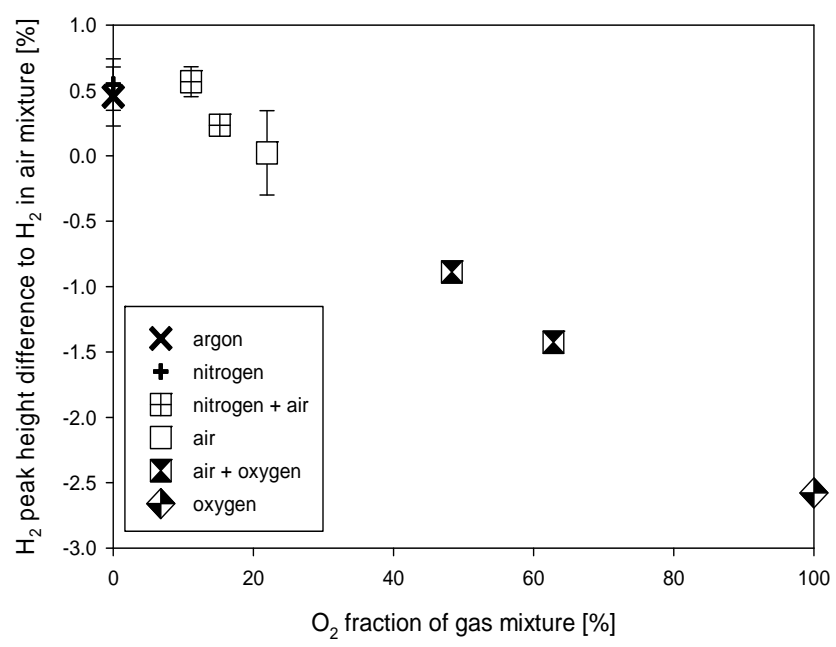

Fig. 10. Dependence of the detector response on the oxygen content. Displayed are the differences between the assigned $\mathrm{H}_{2}$ concentration based on the calibration with $\mathrm{H}_{2}$-in-air mixtures and the $\mathrm{H}_{2}$ concentration as it was mixed (extended from Jordan, 2009).

support for the adequate description of the $\mathrm{HgO}$-reduction detector response.

\section{Summary and conclusions}

This study has investigated factors that are limiting the accuracy of atmospheric hydrogen measurements. Major limitations that have been identified include the availability of reference standards, the stability of the standard gas composition over time, the non-linearity of the prevalent detecting principle and its dependence on the composition of the standard gas matrix. 
A great variability in the properties of different aluminium cylinders with respect to maintaining stable $\mathrm{H}_{2}$ mixing ratios is observed ranging from no detectable drift to $\mathrm{H}_{2}$ growth rates $>20 \mathrm{ppb} \mathrm{yr}^{-1}$. In contrast, steel cylinders are generally found to be suitable containers for $\mathrm{H}_{2}$ reference gases.

A method for the production of precisely defined mixtures of $\mathrm{H}_{2}$ in hydrogen free air or other gases has been set-up. The method is a straightforward alternative to the costly procedure of gravimetric preparations of calibration standards that has limited the rate of preparation of standards in many laboratories. It has been used to produce more than 100 individual $\mathrm{H}_{2}$ standards in real air and other gases. Evaluation of the factors that influence the accuracy of the method results in an uncertainty estimate of $0.3 \%$ for the procedure. The analysis results of 52 air mixtures covering a range of $50-1250 \mathrm{ppb}$ were used to characterize the response function of the commonly used GC-HgO-reduction detector. Over this range of mixing ratios the response curve cannot be adequately described with a 3rd order polynomial function but is better characterized with a function with exponential and quadratic terms. Comparison of $\mathrm{HgO}$-reduction analysis data of $\mathrm{H}_{2}$ in gas mixtures with different oxygen contents revealed a dependence of the signal on the oxygen content of the matrix gas. This demonstrates the importance to calibrate the GC$\mathrm{HgO}-$ reduction analyser with air mixtures.

The cylinder that was used for this gravimetric mixing needed to meet the mass limits for the balance but was not suitable for long-term storage of hydrogen in air mixtures. Therefore, these reference mixtures were discarded after thorough analysis. Their analysis results were used to assign hydrogen mixing ratios to 13 standard gases (listed in Table 1). In metrological terms these standards are not "primary" standards (Brown and Milton, 2007) as the GC analysis does not qualify as primary method. Yet, this set of standards fulfils the basic requirements for a calibration scale as it is stable in time, comparable and coherent with measurements using alternative technologies. This is verified by repeated analysis of these standards with the GC-HePDD technique yielding very small residuals applying a linear response fit.

The 13 standards constitute a new $\mathrm{H}_{2}$ calibration scale that is identified as MPI-2009 $\mathrm{H}_{2}$ scale. It has recently been accepted by the community of experts within the World Meteorological Organization (WMO) as $\mathrm{WMO}_{2}$ mole fraction scale and such serves as reference material for atmospheric observations within the Global Atmosphere Watch (GAW) program. This agreement is a first step towards obtaining a global, integrated database for $\mathrm{H}_{2}$ monitoring data.
Acknowledgements. This work was financially supported and carried out under the auspices of the 6th EU framework program \# FP6-2005-Global-4 "EUROHYDROS - A European Network for Atmospheric Hydrogen Observations and Studies". Michael Targan and Frank Hilbert are acknowledged for their support in the laboratory. CSIRO intercomparison data are by courtesy of R. L. Langenfelds and L. P. Steele. Numerous colleagues have contributed with helpful discussions. Suggestions from Willi Brand, Samuel Hammer, Ray Langenfelds, and Martin Vollmer are gratefully acknowledged.

The service charges for this open access publication have been covered by the Max Planck Society.

Edited by: B. Buchmann

\section{References}

Aalto, T., Lallo, M., Hatakka, J., and Laurila, T.: Atmospheric hydrogen variations and traffic emissions at an urban site in Finland, Atmos. Chem. Phys., 9, 7387-7396, doi:10.5194/acp-97387-2009, 2009.

Aluminum Association: International Alloy Designations and Chemical Composition Limits for Wrought Aluminum and Wrought Aluminum Alloys, http://www.aluminum.org/ Content/NavigationMenu/TheIndustry/IndustryStandards/ Teal_Sheet_Final_031009_PRINTED.pdf, last access: 7 October, 2010.

Bever, M. B.: Encyclopedia of material science and engineering, Pergamon Press, Oxford, UK, 1986.

Beyer, B., Cyrener, E., Grahl, F., Holze, J., Molle, W., and Paul, M.: Tabellenbuch Aluminiumwerkstoffe, 2, VEB Deutscher Verlag für Grundstoffindustrie, Leipzig, Germany, 1986.

Bonasoni, P., Calzolari, F., Colombo, T., Corazza, E., Santaguida, R., and Tesi, G.: Continuous $\mathrm{CO}$ and $\mathrm{H}_{2}$ measurements at Mt. Cimone (Italy): Preliminary results, Atmos. Environ., 31(7), 959967, 1997.

Bond, S. W., Vollmer, M. K., Steinbacher, M., Henne, S., and Reimann, S.: Atmospheric molecular hydrogen $\left(\mathrm{H}_{2}\right)$ : observations at the high-altitude site Jungfraujoch, Switzerland, Tellus B, 63(1), 64-76, doi:10.1111/j.1600-0889.2010.00509.x, 2011.

Brown, R. J. C. and Milton, M. J. T.: Developments in accurate and traceable chemical measurements, Chem. Soc. Rev., 36, 904 913, 2007.

Ehhalt, D. H. and Rohrer, F.: The tropospheric cycle of $\mathrm{H}_{2}$ : a critical review, Tellus B, 61(3), 500-535, doi:10.1111/j.16000889.2009.00416.x, 2009.

Francey, R. J., Steele, L. P., Langenfelds, R. L., Lucarelli, M. P., Allison, C. E., Beardsmore, D. J., Coram, S. A., Derek, N., de Silva, F. A., Etheridge, D. M., Fraser, P. J., Henry, R. J., Turner, B., Welch, E. D., Spencer, D. A., and Cooper, L. N.: Global Atmospheric Sampling Laboratory (GASLAB): supporting and extending the Cape Grim trace gas program, in: Baseline Atmospheric Program Australia 1993, Bureau of Meteorology and CSIRO Division of Atmospheric Research, Melbourne, 23-25, 1996. 
Grant, A., Witham, C. S., Simmonds, P. G., Manning, A. J., and O'Doherty, S.: A 15 year record of high-frequency, in situ measurements of hydrogen at Mace Head, Ireland, Atmos. Chem. Phys., 10, 1203-1214, doi:10.5194/acp-10-1203-2010, 2010a.

Grant, A., Stanley, K. F., Henshaw, S. J., Shallcross, D. E., and O'Doherty, S.: High-frequency urban measurements of molecular hydrogen and carbon monoxide in the United Kingdom, Atmos. Chem. Phys., 10, 4715-4724, doi:10.5194/acp-10-47152010, 2010b.

Hammer, S. and Levin, I.: Seasonal variation of the molecular hydrogen uptake by soils inferred from continuous atmospheric observations in Heidelberg, southwest Germany, Tellus B, 61(3), 556-565, doi:10.1111/j.1600-0889.2009.00417.x, 2009.

Hammer, S., Vogel, F., Kaul, M., and Levin, I.: The $\mathrm{H}_{2} / \mathrm{CO}$ ratio of emissions from combustion sources: comparison of top-down with bottom-up measurements in southwest Germany, Tellus B, 61(3), 547-555, doi:10.1111/j.1600-0889.2009.00418.x, 2009.

IMECC - Infrastructure for Measurements of the European Carbon Cycle: Sausage Flask Intercomparison, http://imecc.ipsl.jussieu.fr/web_na3/index.php?p= ts_lsce_all\&rub=r12\&smenu=smenuInfo1, last access: 18 February, 2011.

Jordan, A.: Calibration of atmospheric hydrogen, in: Proceedings of the 14th WMO/IAEA meeting of experts on carbon dioxide, other greenhouse gases and related tracers measurement techniques, edited by: Laurila, T., WMO Technical Document No. 1487, World Meteorological Organisation, Geneva, CH, 2125, 2009.

Kehiaian, H. V.: Virial coefficients of selected gases, in: CRC Handbook of Chemistry and Physics, 77, edited by: Lide, D. R., CRC Press, Boca Raton, USA, 6.27-6.46, 1997.

Khalil, M. A. K. and Rasmussen, R. A.: Global increase of atmospheric molecular-hydrogen, Nature, 347(6295), 743-745, 1990.

Lallo, M., Aalto, T., Hatakka, J., and Laurila, T.: Hydrogen soil deposition at an urban site in Finland, Atmos. Chem. Phys., 9, 8559-8571, doi:10.5194/acp-9-8559-2009, 2009.

Langenfelds, R. L., Francey, R. J., Pak, B. C., Steele, L. P., Lloyd, J., Trudinger, C. M., and Allison, C. E.: Interannual growth rate variations of atmospheric $\mathrm{CO}_{2}$ and its delta ${ }^{13} \mathrm{C}, \mathrm{H}_{2}, \mathrm{CH}_{4}$, and CO between 1992 and 1999 linked to biomass burning, Global Biogeochem. Cy., 16(3), 1048, doi:10.1029/2001GB001466, 2002.

Masarie, K. A., Langenfelds, R. L., Allison, C. E., Conway, T. J., Dlugokencky, E. J., Francey, R. J., Novelli, P. C., Steele, L. P., Tans, P. P., Vaughn, B., and White, J. W. C.: NOAA/CSIRO Flask Air Intercomparison Experiment: A strategy for directly assessing consistency among atmospheric measurements made by independent laboratories, J. Geophys. Res., 106(D17), 2044520464, 2001.

Monson, L., Moon, S. I., and Extrand, C. W.: Gas Permeation Resistance of Various Grades of PerfluoroalkoxyPolytetrafluoroethylene Copolymers, J. Appl. Polym. Sci., 111(1), 141-147, doi:10.1002/app.28858, 2009.

Necki, J. M., Heliasz, M., Rosiek, J., Pycia, M., Rozanski, K., Sliwka, L., and Bartyzel, J.: Detection of atmospheric hydrogen using ECD detector doped with $\mathrm{N}_{2} \mathrm{O}$, Chem. Anal.-Warsaw, 54(4), 705-716, 2009.

NOAA, NASA, USAF: U.S. Standard Atmosphere 1976, U.S. Government Printing Office, Washington, DC, USA, 1976.
NOAA-ESRL-GMD Standard Reference Gases: Products and Services, http://www.esrl.noaa.gov/gmd/ccl/services.html, last access: 7 October, 2010.

Novelli, P. C., Lang, P. M., Masarie, K. A., Hurst, D. F., Myers, R., and Elkins, J. W.: Molecular hydrogen in the troposphere: Global distribution and budget, J. Geophys. Res., 104(D23), 30427-30444, 1999.

Novelli, P. C., Crotwell, A. M., and Hall, B. D.: Application of gas chromatography with a pulsed discharge helium ionization detector for measurements of molecular hydrogen in the atmosphere, Environ. Sci. Technol., 43(7), 2431-2436, doi:10.1021/es803180g, 2009.

Ostermann, F.: Anwendungstechnologie Aluminium, Springer, Berlin, Germany, 1998.

Paglia, G., Buckley, C. E., Udovic, T. J., Rohl, A. L., Jones, F., Maitland, C. F., and Connolly, J.: Boehmite-derived $\gamma$-alumina system, 2. Consideration of hydrogen and surface effects: consideration of hydrogen and surface effects, Chem. Mater., 16, 1914-1923, 2004.

Park, S. Y., Kim, J. S., Lee, J. B., Esler, M. B. Davis, R. S., and Wielgosz, R. I.: A redetermination of the argon content of air for buoyancy corrections in mass standard comparisons, Metrologia, 41(6), 387-395, 2004.

Prather, M. J.: An environmental experiment with $\mathrm{H}_{2}$ ?, Science, 302(5645), 581-582, 2003.

Schmidt, U.: Molecular-hydrogen in atmosphere, Tellus, 26(1-2), 78-90, 1974.

Schmidt, U. and Seiler, W.: A new method for recording molecular hydrogen in atmospheric air, J. Geophys. Res., 75(9), 17131716, 1970.

Simmonds, P. G., Derwent, R. G., O’Doherty, S., Ryall, D. B., Steele, L. P., Langenfelds, R. L., Salameh, P., Wang, H. J., Dimmer, C. H., and Hudson, L. E.: Continuous high-frequency observations of hydrogen at the Mace Head baseline atmospheric monitoring station over the 1994-1998 period, J. Geophys. Res., 105(10), 12105-12121, 2000.

Simmonds, P. G., Derwent, R. G., Manning, A. J., Grant, A., O'Doherty, S., and Spain, T. G.: Estimation of hydrogen deposition velocities from 1995-2008 at Mace Head, Ireland using a simple box model and concurrent ozone depositions, Tellus B, 63(1), 40-51, doi:10.1111/j.1600-0889.2010.00518.x, 2011.

Steinbacher, M., Fischer, A., Vollmer, M. K., Buchmann, B., Reimann, S., and Hueglin, C.: Perennial observations of molecular hydrogen $\left(\mathrm{H}_{2}\right)$ at a suburban site in Switzerland, Atmos. Environ., 41(10), 2111-2124, doi:10.1016/j.atmosenv.2006.10.075, 2007.

Tohjima, Y., Machida, T., Watai, T., Akama, I., Amari, T., and Moriwaki, Y.: Preparation of gravimetric standards for measurements of atmospheric oxygen and reevaluation of atmospheric oxygen concentration, J. Geophys. Res., 110(D11), D11302, doi:10.1029/2004JD005595, 2005.

Vollmer, M. K., Juergens, N., Steinbacher, M., Reimann, S., Weilenmann, M., and Buchmann, B.: Road vehicle emissions of molecular hydrogen $\left(\mathrm{H}_{2}\right)$ from a tunnel study, Atmos. Environ., 41(37), 8355-8369, doi:10.1016/j.atmosenv.2007.06.037, 2007.

Wang, Z. G., Chen, T. L., and Xu, J. P.: Gas transport properties of a series of cardo polyarylethers, J. Appl. Polym. Sci., 83(4), 791-801, 2002. 
Wieser, M. E. and Berglund, M.: Atomic weights of the elements. Review 2007 (IUPAC Technical Report), Pure Appl. Chem., 81(11), 2131-2156, doi:10.1351/PAC-REP-09-08-03, 2009.

WMO: WMO Global Atmosphere Watch (GAW) Strategic Plan (2008-2015), GAW Report No. 172 (WMO TD NO. 1384), ftp://ftp.wmo.int/Documents/PublicWeb/arep/gaw/ gaw172-26sept07.pdf,, last access: 18 February 2011, World Meteorological Organization, Geneva, Switzerland, 104 pp., 2007.

Xiao, X., Prinn, R. G., Simmonds, P. G., Steele, L. P., Novelli, P. C., Huang, J., Langenfelds, R. L., O’Doherty, S., Krummel, P. B., Fraser, P. J., Porter, L. W., Weiss, R. F., Salameh, P., and Wang, R. H. J.: Optimal estimation of the soil uptake rate of molecular hydrogen from the Advanced Global Atmospheric Gases Experiment and other measurements, J. Geophys. Res., 112(D7), D07303, doi:10.1029/2006JD007241, 2007.
Yver, C., Schmidt, M., Bousquet, P., Zahorowski, W., and Ramonet, M.: Estimation of the molecular hydrogen soil uptake and traffic emissions at a suburban site near Paris through hydrogen, carbon monoxide, and radon-222 semicontinuous measurements, J. Geophys. Res., 114, D18304, doi:10.1029/2009JD012122, 2009.

Yver, C., Pison, I., Fortems-Cheiney, A., Schmidt, M., Bousquet, P., Ramonet, M., Jordan, A., Søvde, A., Engel, A., Fisher, R., Lowry, D., Nisbet, E., Levin, I., Hammer, S., Necki, J., Bartyzel, J., Reimann, S., Vollmer, M. K., Steinbacher, M., Aalto, T., Maione, M., Arduini, I., O’Doherty, S., Grant, A., Sturges, W., Lunder, C. R., Privalov, V., and Paramonova, N.: A new estimation of the recent tropospheric molecular hydrogen budget using atmospheric observations and variational inversion, Atmos. Chem. Phys. Discuss., 10, 28963-29005, doi:10.5194/acpd-1028963-2010, 2010. 